\title{
Pengujian Karateristik Pengisian Baterai Dari Generator DC Magnet Permanen Menggunakan Solar Charging Controller
}

\author{
Herris Yamashika ${ }^{1}$, Mahyessie Kamil ${ }^{2}$ \\ Fakultas Teknik, Universitas Muhammadiyah Sumatera Barat ${ }^{1,2}$ \\ Email: herrisyamashika@umsb.ac.id ${ }^{1}$, mahyessiekamil@umsb.ac.id \\ DOI: http://dx.doi.org/10.31869/rtj.v4i1.2280
}

\begin{abstract}
Abstrak: Penelitian ini melakukan pengujian karateristik pengisian baterai yang menggunakan generator DC magnet permanen sebagai sumber, dan pengaturan pengisian baterai menggunakan Solar Charging Controller (SCC) yang sering dipakai sebagai pengatur pengisian dari panel surya. Pengujian ini dilakukan untuk mengetahui nilai tegangan dan rpm minimal generator agar baterai dapat terisi. Pelaksanaan pengujian dilakukan menggunakan generator DC magnet permanen dengan kapasitas 250 watt, 24 Volt, pada putaran 2750 rpm. Genarator ini dihubungkan ke SCC untuk mengatur pengisian baterai VRLA 12 Volt 7 Ah, dan beban lampu 12 Volt 5 Watt sebanyak 20 buah. Sebagai penggerak mula, digunakan motor induksi 3 fasa yang putarannya dapat diatur melalui Variable Speed Drive (VSD). Parameter arus dan tegangan dari masing-masing generator, baterai, dan beban lampu akan diamati. Untuk mengetahui putarang generator, rpm meter digunakan untuk mengetahui putaran generator. Dari hasil pengujian diperoleh bahwa tegangan minimum generator agar dapat mengisi baterai adalah 12.3 Volt pada putaran $1630 \mathrm{rpm}$.
\end{abstract}

\section{Keywords: Pengisian Baterai, Generator DC Magnet Permanen, Pengujian Karateristik}

\section{PENDAHULUAN}

Penggunaan sumber energi baru dan terbarukan telah mengalami peningkatan, seiring semakin menipisnya cadangan energi fosil. Salah satu sumber energi terbarukan yang melimpah di kondisi geografis negara kita adalah sumber daya air. Air dapat dimanfaatkan untuk membangkitkan daya listrik mulai dari skala watt sampai skala mega watt. Pembangkit listrik tenaga mikro hidro (PLTMH) telah menjadi salah satu alternatif untuk memenuhi kebutuhan listrik skala kecil. Daya listrik dengan kapasitas <1 $\mathrm{kW}$ dapat dibangkitkan menggunakan aliran air sungai yang tidak membutuhkan bendungan. Listrik pada PLTMH dibangkitkan oleh generator sinkron yang keluarannya berupa tegangan arus bolak-balik $(A C)$. Listrik $A C$ harus menghasilkan frekuensi yang relatif stabil, agar tidak merusak peralatan. Pengaturan kestabilan frekuensi dilakukan menggunakan governor untuk mengatur kecepatan putaran turbin atau penggerak mula.

Alternatif lain pembangkitkan listrik adalah Generator DC. Dimana generator DC jenis magnet permanen yang sering digunakan pada pembangkit listrik tenaga bayu (PLTB) banyak tersedia di pasaran, dan harga yang relatif lebih murah dibandingkan jenis generator lain dengan kapasitas yang sama. Kelebihan lain generator DC dari sisi teknis adalah dapat dioperasikan tanpa perlu memperhatikan kestabilan frekuensi, sehingga tidak membutuhkan governor. Penggunaan generator DC pada aliran air yang tidak konstan akan meyebabkan fluktuasi tegangan keluaran. Agar dapat dimanfaatkan secara optimal, listrik keluaran generator DC disimpan di baterai. Skema ini seperti yang digunakan pada pemanfaatan tenaga matahari, dimana listrik yang dihasilkan oleh sel Photo Voltaic (PV) akan diatur oleh Solar Charging Controller (SCC), sehingga bisa digunakan untuk mengisi baterai dan memasok daya ke beban. Namun pemanfaatan energi surya sangat bergantung kepada irradiance dan temperatur dari cahaya matahari, dan hanya dapat dilakukan pada siang hari. Berbeda halnya dengan potensi air, pemanfaatan energi air dapat dilakukan sepanjang waktu.

Penggunaan generator DC magnet permanen yang biasa digunakan oleh PLTB untuk pengisian baterai perlu dilakukan uji kinerja ketika beroperasi. Penelitian ini akan melakukan pengujian pada penggunaan generator DC tersebut untuk pengisian baterai pada kondisi putaran generator yang bervariasi. Setelah dilakukan pengujian kinerja sistim, penelitian tahap berikutnya dapat dilakukan pengembangan untuk mengoptimalkan pengisian. 
Salah satu cara mendapatkan sumber energi listrik terbarukan yang berasal dari alam adalah dengan menyimpan energi tersebut di media penyimpanan, salah satunya adalah baterai. Daya listrik yang dibangkitkan dari cahaya matahari sangat fluktuatif, sehingga bila dimanfaatkan langsung tidaklah efektif dan efisien. Cara yang paling ideal memanfaatkan energi matahari adalah melalui penyimpanan di baterai. Daya listrik yang dihasilkan akan digunakan untuk mengisi baterai. Strategi pengisian baterai dan pengaturan beban dari sel PV tunggal telah dilakukan oleh (Harrington \& Dunlop, 1992). Beberapa algoritma pengisian ditampilkan, bersama dengan terminologi yang digunakan di industri PV untuk battery charging controller. Informasi yang diperoleh dari evaluasi terhadap charging controller yang tersedia di pasaran dibahas bersaman data yang diperoleh dari hasil pengujian di lapangan. Hasil yang diperoleh adalah karateristik kinerja baterai yang dibutuhkan desain dan pengoperasian PV untuk jangka waktu yang lama.

Teknologi pengisian baterai mengalami perkembangan, dimana masing-masing jenis baterai memiliki algoritma pengisian tersendiri.. (Park et al., 2008) mencari algoritma pengisian yang dapat digunakan secara universal pada jenis baterai yang berbeda. Algoritma yang cocok untuk suatu jenis baterai diperoleh dari analisis karateristik baterai tersebut. Algoritma universal ini bekerja dengan mendeteksi inflection point, treshold point, dan termination point. Hasil yang diperoleh, algoritma universal ini mampu mengisi untuk jenis baterai, diantaranya $\mathrm{Ni}$ Cd, Ni-MH, SLA, Li-Ion dari 2V sampai 18V, Ni-MH, SLA, and Li-Ion.

Penyimpanan energi listrik terbarukan pada baterai secara umum berasal dari energi surya. Pengisian baterai diatur oleh charging controller, dengan menggunakan algoritma tertentu. Penelitian ini akan mengambil celah untuk menguji karateristik pengisian baterai yang berasal generator DC magnet permanen pada putaran yang berubah-rubah. Putaran yang tidak konstan ini merupakan representai dari aliran air ketika generator dc magnet permanen tersebut digunakan sebagai pembangkit PLTMH.

Penelitian ini bertujuan untuk mendapatkan nilai minimal tegangan dan putaran generator DC magnet permanen agar bisa mengisi baterai melalui SCC.

\section{METODE PENELITIAN}

Penelitian ini dilaksanakan dengan memutar generator DC magnet permanen dengan kecepatan yang bervariasi. Generator diputar oleh motor induksi 3 fasa yang terhubung dengan variable speed drive, sehingga putaran motor induksi tersebut dapat dirubah sesusai kebutuhan. Generator DC yang digunakan adalah tipe magnet permanen, dengan kapasitas 250 watt, tegangan 24 Volt, dan putaran $2750 \mathrm{rpm}$. Keluaran generator tersebut disambungkan ke charging controller, dimana dalam hal ini yang akan digunakan adalah solar charging controller (SCC) jenis pulse width modulation (PWM). SCC akan mengatur pengisian ke baterai dan keluaran ke beban DC. Untuk mendapatkan data parameter, alat ukur dipasang diantaranya voltmeter, amperemeter, dan tachometer. Diagram lengkap komponen yang digunakan pada penelitian ini seperti yang terlihat pada gambar 1.

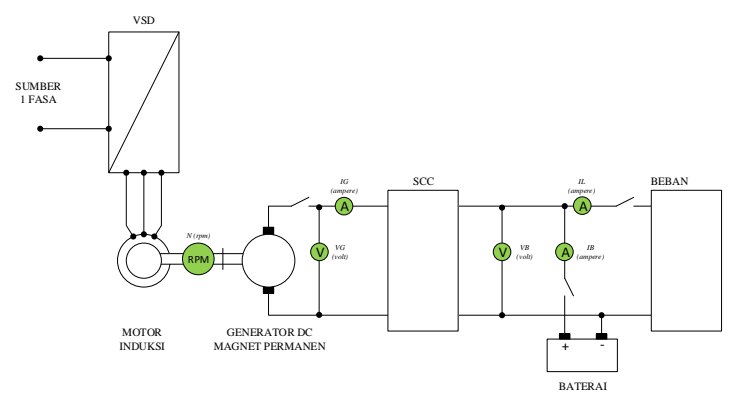

Gambar 1. Skematik Peralatan Penelitian

Skenario yang digunakan adalah tegangan generator tanpa beban diatur pada nilai 14 Volt. Kemudian dilakukan pengisian baterai tanpa beban lampu, dan kemudian dilanjutkan dengan menambahkan beban lampu secara bertahap dari 1 buah lampu sampai 10 buah lampu. Setiap penambahan beban baterai dan lampu diambil data untuk parameter berikut :

- Tegangan generator $\left(V_{g e n}\right)$,

- Arus generator $\left(I_{g e n}\right)$,

- Arus baterai $\left(I_{\text {batt }}\right)$,

- Arus beban $\left(I_{\text {load }}\right)$

- Tegangan beban $\left(V_{\text {load }}\right)$,

- Putaran generator (rpm). 


\section{HASIL DAN PEMBAHASAN}

Rancangan peralatan penelitian seperti yang disampaikan sebelumnya dilajutkan dengan tahap pembuatan alat, sesuai dengan skematok pada Gambar 1. Hasil pembuatan peralatan seperti pada gambar 2 .
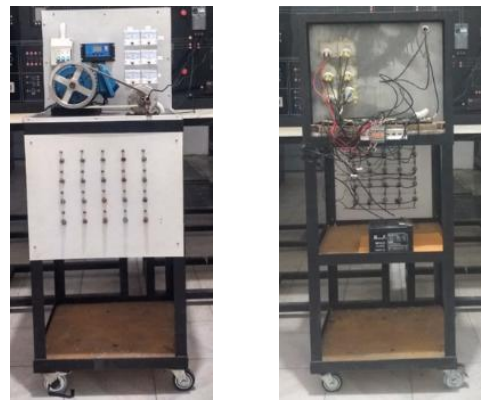

Gambar 2. Alat Penelitian

Hasil yang diperoleh dari pengambilan data sesuai skenario telah disebutkan sebelumnya adalah sebagai berikut :

\begin{tabular}{|c|c|c|c|c|}
\hline \multirow[b]{2}{*}{ Battery } & \multirow[b]{2}{*}{$\begin{array}{l}\text { No. of } \\
\text { Load }\end{array}$} & \multicolumn{3}{|c|}{ Generator } \\
\hline & & $\begin{array}{l}\text { Vgen } \\
\text { (Volt) }\end{array}$ & $\begin{array}{l}\text { Igen } \\
\text { (A) }\end{array}$ & $\begin{array}{c}\text { Pgen } \\
\text { (Watt) }\end{array}$ \\
\hline$x$ & $x$ & 14.00 & 0.02 & 0.21 \\
\hline $\mathrm{V}$ & $\mathrm{x}$ & 13.50 & 0.40 & 5.40 \\
\hline $\mathrm{v}$ & 1 & 12.80 & 0.90 & 11.52 \\
\hline $\mathrm{v}$ & 2 & 12.30 & 1.38 & 16.97 \\
\hline $\mathrm{v}$ & 3 & 11.90 & 2.00 & 23.80 \\
\hline $\mathrm{v}$ & 4 & 11.50 & 2.04 & 23.46 \\
\hline $\mathrm{v}$ & 5 & 11.30 & 2.19 & 24.75 \\
\hline $\mathrm{v}$ & 6 & 11.20 & 2.33 & 26.10 \\
\hline $\mathrm{v}$ & 7 & 11.10 & 2.41 & 26.75 \\
\hline $\mathrm{v}$ & 8 & 11.00 & 2.50 & 27.50 \\
\hline $\mathrm{v}$ & 9 & 10.80 & 2.55 & 27.54 \\
\hline $\mathrm{v}$ & 10 & 10.80 & 2.62 & 28.30 \\
\hline $\mathrm{v}$ & 11 & 10.70 & 2.70 & 28.89 \\
\hline
\end{tabular}

Tabel 1. Parameter Generator

\begin{tabular}{|c|c|c|c|c|}
\hline \multirow{2}{*}{ Battery } & \multirow{2}{*}{$\begin{array}{c}\text { No. of } \\
\text { Load }\end{array}$} & $\begin{array}{c}|c| \\
\text { Vload } \\
\text { (Volt) }\end{array}$ & $\begin{array}{c}\text { Iload } \\
\text { (A) }\end{array}$ & $\begin{array}{c}\text { Pload } \\
\text { (Watt) }\end{array}$ \\
\hline \hline $\mathrm{x}$ & $\mathrm{x}$ & 0.00 & 0.00 & 0.00 \\
\hline $\mathrm{v}$ & $\mathrm{x}$ & 0.00 & 0.00 & 0.00 \\
\hline $\mathrm{v}$ & 1 & 12.90 & 0.75 & 9.68 \\
\hline $\mathrm{v}$ & 2 & 12.20 & 1.43 & 17.45 \\
\hline $\mathrm{v}$ & 3 & 11.60 & 2.04 & 23.66 \\
\hline $\mathrm{v}$ & 4 & 11.10 & 2.67 & 29.64 \\
\hline $\mathrm{v}$ & 5 & 10.90 & 3.32 & 36.19 \\
\hline $\mathrm{v}$ & 6 & 10.60 & 3.92 & 41.55 \\
\hline $\mathrm{v}$ & 7 & 10.50 & 4.50 & 47.25 \\
\hline $\mathrm{v}$ & 8 & 10.30 & 5.10 & 52.53 \\
\hline $\mathrm{v}$ & 9 & 10.10 & 5.80 & 58.58 \\
\hline $\mathrm{v}$ & 10 & 10.00 & 6.41 & 64.10 \\
\hline $\mathrm{v}$ & 11 & 9.90 & 6.96 & 68.90 \\
\hline
\end{tabular}

Tabel 2. Parameter Beban

\begin{tabular}{|c|c|c|c|}
\hline \multirow{2}{*}{ Battery } & \multirow{2}{*}{$\begin{array}{c}\text { No. of } \\
\text { Load }\end{array}$} & $\begin{array}{c}|c| \\
\text { Ibatt } \\
\text { (A) }\end{array}$ & Status \\
\hline \hline X & X & 0.00 & off \\
\hline v & X & 0.38 & charging \\
\hline v & 1 & 0.13 & charging \\
\hline v & 2 & 0.05 & charging \\
\hline v & 3 & -0.30 & loading \\
\hline v & 4 & -0.65 & loading \\
\hline v & 5 & -1.12 & loading \\
\hline v & 6 & -1.57 & loading \\
\hline v & 7 & -2.10 & loading \\
\hline v & 8 & -2.60 & loading \\
\hline v & 9 & -3.14 & loading \\
\hline v & 10 & -3.62 & loading \\
\hline v & 11 & -4.00 & loading \\
\hline
\end{tabular}

Tabel 3. Parameter Bterai

Tabel 1 sampai 3 memperlihatkan kondisi pengisian baterai ketika terjadi penambahan beban. Pada kondisi generator tanpa beban tegangan diatur pada 14 Volt, dengan rpm $1883 \mathrm{rpm}$. Kemudian generator dibebani untuk mengisi baterai melalui SCC tanpa beban lampu, arus pengisian baterai $\left(\mathrm{I}_{\text {batt }}\right.$ ) sebesar 0.38 Ampere dengan tegangan keluaran generator $\left(\mathrm{V}_{\text {gen }}\right)$ sebesar 13.5 Volt. Ketika dilakukan penambahan beban lampu sebanyak 1 buah, arus pengisian baterai turun menjadi 0,13 Ampere dan tegangan generator menjadi 12,8 Volt. Baterai akan tetap terisi (charging) sampai jumlah beban yang dihidupkan sebanyak 2 buah, dimana arus pengisian baterai $\left(\mathrm{I}_{\text {batt }}\right)$ menjadi 0.05 Ampere, dan tegangan generator $\left(\mathrm{V}_{\text {gen }}\right)$ menjadi 12.3 Volt. Pada kondisi ini putaran generator sebesar $1630 \mathrm{rpm}$.

Pembebanan ditambah dengan mengidupkan beban lampu sebanyak 3 buah, hasil pengukuran memperlihat bahwa baterai tidak lagi pada kondisi charging, namun memasok daya (loading). Tegangan generator menjadi 11.9 Volt, dan arus dari baterai ke arah beban adalah 0.3 Ampere. Keadaan ini terus berlanjut jika beban lampu ditambah. Pada saat beban lampu hidup sebanyak 10 buah, tegangan generator $\left(\mathrm{V}_{\text {gen }}\right)$ turun menjadi 10.8 Volt.

\section{SIMPULAN}

1. Nilai minimal tegangan generator agar dapat mengisi baterai adalah 12.3 Volt, jika tegangan generator dibawah nilai tersebut 
maka baterai tidak lagi terisi dan akan memasok daya ke beban.

2. Putaran generator minimal agar dapat mengisi baterai adalah $1630 \mathrm{rpm}$, jika putaran generator dibawah nilai tersebut maka baterai tidak lagi terisi dan akan memasok daya ke beban.

\section{UCAPAN TERIMAKASIH}

Ucapan terima kasih dipersembahkann kepada LPPM UMSB dan Pimpinan UMSB. Penelitian ini terlaksana atas pendanaan melaluii skema hibah internal penelitian UMSB.

\section{DAFTAR PUSTAKA}

Harrington, S., \& Dunlop, J. (1992). Battery Charge Controller Characteristics in Photovoltaic Systems. IEEE AES Magazine, (August).

Kenjo, T., \& Nagamori, S. (1985). Permanent Magnet and Brusless DC Motor. Oxford University Press.

Park, S., Miwa, H., Clark, B. T., Ditzler, D. S. K., Malone, G., \& Neil, S. D. (2008). A Universal Battery Charging Algorithm for Ni- Cd, Ni-MH , SLA, and Li-Ion for Wide Range Voltage in Portable Applications. In 2008 IEEE Power Electronics Specialists Conference (pp. 4689-4694).

Priya, R. (2016). Generalized Mathematical Modeling and Analysis of a PMDC Generator. International Journal of Research and Discovery, 2(June), 18-20. 